\title{
Bromocriptine in Parkinson's disease: a study of cardiovascular effects
}

\author{
N I A L L Q U IN N,**A C H I L L ILLA S,** FRAN ÇO IS LHERM ITTE, \\ A N D Y VES A G I \\ From the Clinique de Neurologie et Neuropsychologie, Hôpital de la Salpétrière, Paris
}

\begin{abstract}
SUMMARY Blood pressure and pulse rate were studied in 20 Parkinsonian patients on no treatment, and during treatment with bromocriptine (mean dosage $148 \mathrm{mg} /$ day) as the sole anti-Parkinsonian therapy. The drug was shown to reduce erect systolic and diastolic and supine systolic blood pressure and to increase erect pulse rate, in a predictable dose-dependent manner. The occurrence of episodes of significant postural hypotension was less predictable and was a transitory phenomenon in all patients. Peripheral dopamine receptor blockade with domperidone did not alter the findings, suggesting that the principal mechanism for these cardiovascular effects is a central dopaminergic one.
\end{abstract}

In Parkinson's disease oral levodopa lowers systolic and diastolic blood pressure both in the lying and, to a greater degree, in the standing position. ${ }^{1-3}$ When levodopa is administered together with a peripheral DOPA-decarboxylase inhibitor, the same effects are observed, ${ }^{4-6}$ suggesting that levodopa-induced hypotension is principally centrally mediated.

Bromocriptine lowers blood pressure in patients with Parkinson's disease, ${ }^{78}$ acromegaly ${ }^{9}$ and essential hypertension. ${ }^{10} 11$ In the studies cited it was administered either in low dosage, often together with levodopa ${ }^{7}$ or $\alpha$-methyl DOPA, ${ }^{11}$ or as single variable doses. ${ }^{8}$ The antiemetic domperidone, a peripheral dopamine receptor blocker, permits the rapid attainment of high dosages of bromocriptine without diminishing its clinical efficacy in Parkinsonian patients. ${ }^{12} 13$ Using this drug, we therefore made a study of the cardiovascular effects of high dose bromocriptine compared with no treatment, and of bromocriptine plus domperidone compared with bromocriptine plus placebo in the same patients.

*Present address: Department of Neurology, Institute of Psychiatry London SE 5, England.

**Present address: Department of Neurology, Athens, Greece.

Address for reprint requests: Dr Y Agid, Hôpital de la Salpétrière, 75634, Paris Cedex 13, France.

Accepted 10 March 1981

\section{Patients and methods}

Twenty patients with Parkinson's disease were studied. Subjects with a history of symptomatic orthostatic hypotension were excluded. All 17 patients previously on levodopa stopped this medication on admission; all but one stopped all other anti-Parkinsonian medication. One patient already taking a $\beta$-blocker for angina continued with the same dosage. The initial assessment of Parkinsonian and cardiovascular status took place 24-72 hours after stopping treatment, and the last set of results off treatment was taken as the control series. Bromocriptine was then introduced, starting with one $2.5 \mathrm{mg}$ tablet and adding one tablet successively to the three daily doses, giving a constant increase of total dose of $22.5 \mathrm{mg} / \mathrm{day}$. This rapid rate of increase was permitted by the introduction of domperidone $50 \mathrm{mg}$ thrice daily, as an antiemetic. When high clinically optimal (mean improvement over baseline of $75 \%)^{13}$ doses of bromocriptine (mean $148 \mathrm{mg} /$ day) were reached, all 20 patients were taking active domperidone (phase A). Placebo domperidone was then introduced (phase B) in all patients for a period of 1 to 5 (mean 2.2) days.

The patients were studied for 10 to 15 (mean 12) days. Systolic and diastolic pressures (measured manually) and pulse were recorded daily, after 5 minutes supine, immediately on standing, and after 1 minute and 5 minutes erect. Two hundred and thirty-four blood pressure readings were taken. Statistical analysis was performed using the $t$ pair test. 

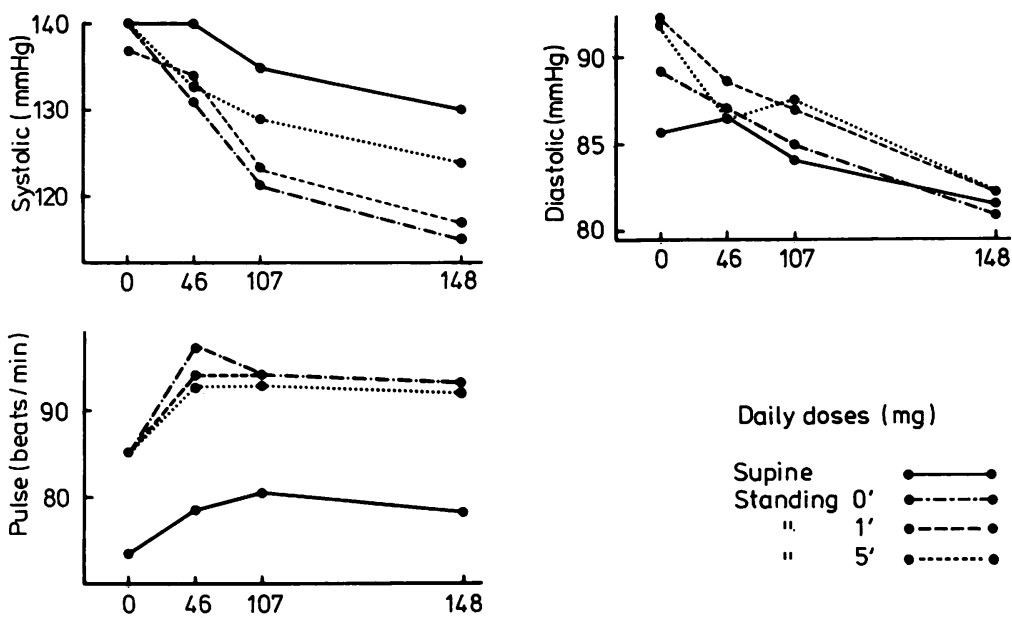

Figure Effect of bromocriptine on blood pressure and pulse as a function of daily dose. Mean values for 20 patients are represented before treatment, after 3, 6 and the mean of last 3 days (corresponding to total mean daily bromocriptine of $0,46,107$ and $148 \mathrm{mg}$ respectively). All changes at the highest doses were significantly different from pre-treatment values with the exception of supine diastolic blood pressure and pulse.

\section{Results}

The comparison of mean blood pressure and pulse for the last three days on high-dose bromocriptine with the last day off all treatment showed that systolic and diastolic blood pressures were significantly lowered in the erect position, but in the supine position only the fall in systolic pressure reached significant levels (figure). Pulse rate rose significantly in all but the supine position. These effects were dose-dependent (figure).

There was no significant change in blood pressure and pulse between the last day of phase A (bromocriptine plus domperidone) and the first day of phase B (bromocriptine plus placebo) (table). Similar results were obtained by comparing the last two days of phase $A$ with the whole of phase B.

Table Blood pressure and pulse in patients treated with bromocriptine with (phase $A$ ) and without (phase B) domperidone

\begin{tabular}{llcc}
\hline Position & & $\begin{array}{c}\text { Last day of phase } \\
\text { A (bromocriptine } \\
\text { placebo) }\end{array}$ & $\begin{array}{l}\text { First day of phase } \\
\text { B(bromocriptine } \\
\text { placebo) }\end{array}$ \\
\hline Supine & Systolic & $132 \pm 3$ & $127 \pm 3$ \\
& Diastolic & $83 \pm 2$ & $81 \pm 2$ \\
Immediately & Pulse & $79 \cdot 3 \pm 2$ & $75 \pm 1$ \\
on standing & Systolic & $115 \pm 5$ & $111 \pm 5$ \\
& Diastolic & $80 \pm 3$ & $77 \pm 3$ \\
After 1 & Pulse & $92 \pm 6$ & $91 \pm 3$ \\
minute & Systolic & $124 \pm 4$ & $120 \pm 5$ \\
standing & Diastolic & $85 \pm 3$ & $81 \pm 3$ \\
After 5 & Pulse & $91 \pm 3$ & $89 \pm 3$ \\
minutes & Systolic & $126 \pm 4$ & $121 \pm 5$ \\
standing & Diastolic & $85 \pm 3$ & $80 \pm 3$ \\
Daily dose of bromocriptine & Pulse & $90 \pm 3$ & $89 \pm 3$ \\
\hline
\end{tabular}

None of the values differed significantly between phases $\mathbf{A}$ and $\mathbf{B}$.
Episodes of significant postural hypotension (defined for the purposes of this study as a fall of more than $30 \mathrm{mmHg}$ in systolic blood pressure on assuming the erect position) occurred at any dosage level of bromocriptine, but with a maximal incidence corresponding to single doses of 40 to $50 \mathrm{mg}$, again falling off at higher dosage levels. Overall 13 of the 20 patients had episodes of significant postural hypotension recorded at least once. Nine patients were affected on only one or two occasions, and three (including the patient taking a $\beta$-blocker) on five or six occasions. Not all of these episodes were symptomatic. Significant postural hypotension was commonest immediately on assuming the erect position, but three patients who were not affected immediately or after one minute developed it only after 5 minutes standing. Significant postural hypotension was recorded on 33 occasions out of a total of 234 series of measurements, two patients being affected severely enough to prevent them from standing for one minute or longer-one patient on two occasions and the other on six consecutive days. All patients were subsequently free of significant postural hypotension on higher doses of bromocriptine.

Twenty-three episodes of significant postural hypotension occurred during treatment with domperidone and 10 during the placebo phase, but the number of patient-days passed in active phases of the trial among the affected subjects exceeded that passed in the placebo phase by a comparable ratio of 2.75 to 1 .

\section{Discussion}

This study confirms that bromocriptine reduces 
both supine and erect systolic, and erect diastolic blood pressures, and increases erect pulse rate in patients receiving high clinically effective dosages as sole anti-Parkinsonian treatment. These effects are shown to be dose-dependent. Although partially in keeping with the findings of Greenacre et $a l^{7}$ the results differ in that we found a significant lowering of supine systolic and of erect diastolic blood pressure where they did not. We also found, in the supine position, a non-significant rise in pulse rate, as opposed to their patients' significant fall. These differences may be due to the fact that in their study the mean dose of bromocriptine was only $46.9 \mathrm{mg} / \mathrm{day}$, and some patients in both control and treatment groups were taking levodopa in addition. Thus, the figure shows that supine systolic blood pressure is significantly lowered only at high dosage levels well above $50 \mathrm{mg} /$ day. The finding of a dose-dependent effect extends the results of an acute single-dose study by Galea Debono et al. ${ }^{8}$

The number of patients (13/20) developing episodes of significant postural hypotension on at least one occasion during the trial is higher than in most series. This may be partly due to the higher dosages and increments of bromocriptine used, but also in part to the large number $(>700)$ of erect blood pressure readings taken. Significant postural hypotension occurred unpredictably: it did not occur in all patients, it was not necessarily symptomatic, and it could arise at any dose, but appeared most frequently after single doses of around $45 \mathrm{mg}$ of bromocriptine. It was also a transitory phenomenon in all patients, subsequently disappearing despite further increase in the dose of bromocriptine. In these respects, it contrasts with the smooth, dose-dependent lowering of blood pressure discussed above. Although collapse of blood pressure has been described occurring after the first, $2.5 \mathrm{mg}$, dose of bromocriptine, ${ }^{71415}$ perhaps on an idiosyncratic basis, none of our patients experienced this. In patients with idiopathic Parkinson's disease, therefore, the appearance of significant postural hypotension is not necessarily an indication for either abandoning bromocriptine, lowering the dose, or altering the rate of dose increase. It should, however, be stressed that patients with a previous history of symptomatic orthostatic hypotension were excluded from this study, and may not be covered by the above comments.

Neither the overall lowering of blood pressure nor the incidence of significant postural hypotension were modified by the concomitant administration of domperidone (table). Since bromocriptine is generally recognised as a dopaminergic agonist, ${ }^{16}$ and domperidone is a peripheral dopamine receptor antagonist, ${ }^{17}$ it suggests that the hypotensive action of the former is achieved principally through a central dopaminergic mechanism.

\section{References}

1 Calne DB, Brennan J, Spiers ASD, and Stern GM. Hypotension caused by L-DOPA. Br Med J 1:474-5.

2 Reid JL, Calne DB, George CF, and Vakil SD. The action of L-DOPA on baroreflexes in parkinsonism. Clin Sci 1972; 43:851-9.

3 Calne DB, Teychenne PF. L-DOPA effect on blood pressure in man. Hypertension and mechanisms. Prog Brain Res 1977; 47:331-6.

4 Watanabe AM, Chase TN, Cardon PV. Effect of L-DOPA alone and in combination with an extracerebral decarboxylase inhibitor on blood pressure and some cardiovascular reflexes. Clin Pharmac Ther 1970; 11:740-6.

5 Liebowitz M, Lieberman A. Comparison of DOPA decarboxylase inhibitor (carbidopa) combined with L-DOPA and L-DOPA alone on the cardiovascular system of patients with Parkinson's disease. Neurology (Minneap) 1973; 25:917-21.

6 Reid JL, Greenacre JK, Teychenne PF. Cardiovascular actions of L-DOPA and dopaminergic agonists in Parkinsonism. In: Birkmayer W, Hornykiewicz $\mathrm{O}$, eds. Advances in Parkinsonism. Roche Editions 1976; 566-73.

7 Greenacre JK, Teychenne PF, Petrie A, Calne DB, Leigh N, Reid JL. The cardiovascular effects of bromocriptine in Parkinsonism. $\mathrm{Br} J$ Clin Pharmacol 1976; 3:571-4.

8 Galea Debono A, Marsden CD, Asselman P, Parkes JD. Bromocriptine and dopamine receptor stimulation. Br J Clin Pharmacol 1976; 3:977-82.

9 Nilsson A, Hokfelt B. Effect of bromocriptine on blood pressure, plasma and urinary catecholamines and plasma renin activity (PRA) in patients with acromegaly. Acta Endocr Copenh 1977; suppl. 212:95.

10 Stumpe KO, Kolloch R, Higuchi M, Kruck F, Vetter H. Hyperprolactinaemia and antihypertensive effect on bromocriptine in essential hypertension. Lancet 1977; ii:211-4.

11 Lewis MJ, Henderson AH. Bromocriptine in Methyldopa treated hypertension: possible role of central dopaminergic activity. Br Heart J 1978; 40:1067-8.

12 Agid Y, Pollak P, Bonnet AM, Signoret JL, Lhermitte F. Bromocriptine associated with a peripheral dopamine blocking agent in treatment of Parkinson's disease. Lancet 1979; i:570-2.

13 Quinn N, Illas A, Lhermitte F, Agid Y. Bromocriptine and domperidone in the treatment of Parkinson's disease. Neurology (Minneap) (in press). 
14 Teychenne PF, Calne DB, Leigh PN, et al. Idiopathic Parkinsonism treated with bromocriptine. Lancet 1975; ii:473-6.

15 Parkes JD, Debono AG, Marsden CD. Bromocriptine in Parkinsonism; long-term treatment, dose response, and comparison with levoda. $J$ Neurol, Neurosurg Pschiatry 1976; 39:1101-8.
16 Agid Y, Barroche G, Bonnet AM, et al. Dopamine receptor stimulating agonists in the treatment of Parkinson's disease. Biomedicine 1979; 30:67-71.

17 Costall B, Fortune DH, Naylor RJ. Neuropharmacological studies on the neuroleptic potential of domperidone (R 33812). J Pharm Pharmacol; 31: 344-7. 